\title{
Association of injury mechanism with the risk of cervical spine fractures
}

\author{
Wendy L. Thompson, MSc; ${ }^{* \dagger}$ Ian G. Stiell, MD, MSc $; \stackrel{+}{\ddagger}$ Catherine M. Clement, RN; $;$ \\ Robert J. Brison, MD, MPH; ${ }^{*}$ for the Canadian C-Spine Rule Study Group
}

\begin{abstract}
Objective: A full understanding of an injury event and the mechanical forces involved should be important for predicting specific anatomical patterns of injury. Yet, information on the mechanism of injury is often overlooked as a predictor for specific anatomical injury in clinical decision-making. We measured the relationship between mechanism of injury and risk for cervical spine fracture.

Methods: Our case-control study is a secondary analysis of data collected from the Canadian C-Spine Rule (CCR) study. Data were collected from 1996 to 2002 and included patients presenting to the emergency departments of 9 tertiary care centres after sustaining acute blunt trauma to the head or neck. Cases are defined as patients who were categorized in the CCR study with a clinically important cervical spine fracture. Controls had no radiologic evidence of cervical spine injury. Bivariate and multivariate unconditional logistic regression models were used. Results are presented as odds ratios (ORs) with $95 \%$ confidence intervals (Cls).

Results: Among the 17208 patients in the CCR study, 320 (2\%) received a diagnosis of a cervical spine fracture. Axial loads, falls, diving incidents and nontraffic motorized vehicle collisions (e.g., collisions involving snowmobiles or all-terrain vehicles) were injury mechanisms that were significantly related to a higher risk of fracture. For motor vehicle collisions, the risk of cervical spine injury increased with the posted speed, being involved in a head-on collision or a rollover, or not wearing a seat belt $(p<0.05)$. The occurrence of cervical spine fracture was negligible in simple rear-end collisions ( 1 in 3694 cases; OR 0.015, 95\% Cl 0.002-0.104]).

Conclusion: Our study quantitatively demonstrates the relationship between specific mechanisms of injury and the risk of a cervical spine fracture. A full understanding of the injury mechanism would assist providers of emergency health care in assessing risk for injury in trauma patients.

Keywords: mechanism of injury, cervical spine injury, case-control study, Canadian C-Spine Rule Study

\section{RÉSUMÉ}

Objectif : Il importe de bien comprendre l'événement traumatique et les forces mécaniques en jeu si l'on veut prévoir la nature anatomique précise de traumatismes. Pourtant, trop souvent, on ne tient pas compte du mécanisme de blessure comme facteur prédictif de traumatismes précis dans le processus décisionnel clinique. Nous avons mesuré le rapport entre le mécanisme de blessure et le risque de fracture de la colonne cervicale.
\end{abstract}

From the *Department of Community Health and Epidemiology, Queen's University, Kingston, Ont., the tHealth Surveillance and Epidemiology Division, Public Health Agency of Canada, Ottawa, Ont., the ¥Department of Emergency Medicine, University of Ottawa, Ottawa, Ont., and the §Department of Emergency Medicine, Queen's University, Kingston, Ont.

Submitted Feb. 5, 2008; Revised July 11, 2008; Accepted Aug. 12, 2008

This article has been peer reviewed.

CJEM 2009;11(1):14-22 
Méthodes : Notre étude cas-témoins est une analyse secondaire de données recueillies de l'étude sur la Règle canadienne concernant la colonne cervicale (Canadian C-Spine Rule ou étude CCR). Les données, collectées de 1996 à 2002, portaient sur des patients s'étant présentés aux urgences de 9 centres de soins tertiaires après avoir subi un traumatisme aigu à la tête ou au cou. Il s'agissait de patients chez qui on avait posé un diagnostic de fracture grave de la colonne cervicale. Le groupe-témoin n'avait pas de preuve radiologique de traumatisme cervical. Nous avons utilisé des modèles de régression logistique bivariés et multivariés inconditionnels. Les résultats sont présentés sous forme de ratio d'incidence approché (RIA) avec des intervalles de confiance (IC) à $95 \%$.

Résultats : Parmi les 17208 patients de l'étude CCR, 320 ont reçu un diagnostic de fracture de la colonne cervicale. Les charges axiales, les chutes, les accidents de plongeon et les collisions avec un véhicule récréatif motorisé ( $p$. ex., collisions impliquant une motoneige, un véhicule tout-terrain) étaient des mécanismes de blessures pour lesquels le risque de fracture de la colonne cervicale était significativement plus élevé. Pour ce qui est des accidents automobiles, le risque de fracture de la colonne cervicale augmentait en fonction des limites de vitesse indiquées, ou lorsqu'il s'agissait de collisions frontales, d'un accident comportant un capotage ou de cas de non-port de la ceinture de sécurité $(p<0,05)$. Les cas de fractures de la colonne cervicale étaient négligeables dans les collisions par I'arrière ( 1 pour 3694 cas, RIA = 0,015, IC à $95 \%$ de 0,002 à 1,04).

Conclusion : Notre étude montre, sur le plan quantitatif, le rapport entre des mécanismes de blessures précis et le risque d'une fracture de la colonne cervicale. Une pleine compréhension de ces mécanismes aidera les fournisseurs de soins de santé des services d'urgence à évaluer les risques de blessures chez les patients ayant subi un traumatisme.

\section{Introduction}

\section{Background}

A full understanding of an injury event and the mechanical forces involved should be important for predicting the likelihood and severity of specific anatomical patterns of injuries. Many clinicians and researchers believe that understanding the mechanism of injury is vital in clinical decision-making for trauma patients and that there is an increasing need to make use of and improve on such information. ${ }^{1-4}$ Although some believe this information is a reliable injury "marker," others suggest that the mechanism of injury is not a useful predictor for injury severity ${ }^{5-7}$ and that clinical criteria alone are effective in predicting which patients have injury, particularly spinal injury. ${ }^{8}$

Observations that stem from the study of anatomical injury patterns in motor vehicle collisions (MVCs) include the occurrence of, among others, chance fractures seen with lap belt use, and cases of hangman fracture, which is a severe extension injury resulting when the face forcibly strikes the dashboard..$^{9-15}$ Other injury mechanisms associated with specific anatomical injury include Lisfranc joint fractures, which often occur from a twisting fall, ${ }^{16}$ Colles fracture, which is most commonly seen in patients who fell on an outstretched hand, ${ }^{17}$ knee dislocation patterns from axial loads ${ }^{18}$ and tracheobronchial injuries. ${ }^{19}$

\section{Importance}

Research that quantitatively assesses the relationship between an injury mechanism and anatomical injury outcomes has been limited, despite observations of specific injury mechanisms being associated with distinct patterns of anatomical injury. The Canadian C-Spine Rule (CCR), ${ }^{20}$ used to predict the absence of cervical spine fracture, is one decision rule that does make use of information on the mechanism of injury.

\section{Goals of our investigation}

In this secondary analysis of CCR study data, information was collected on injury event circumstances for individuals who were at risk for cervical spine injury. This provided a unique opportunity to measure risk for injury related to cervical spine fractures for patients presenting to emergency departments (EDs) with acute blunt trauma to the head or neck. These data were collected prospectively as part of the CCR study. ${ }^{20,21}$ Through collecting detailed information on the injury event, our study assesses the utility of measuring the risk (as odds ratios [ORs]) for one anatomical injury, the clinically important cervical spine injury, that is associated with a series of injury mechanisms.

\section{Methods}

\section{Study design}

Our case-control study is a secondary analysis of the CCR study data, a prospective cohort of individuals with acute blunt trauma to the head or neck who presented to 1 of 9 Canadian community or academic hospital EDs between 
1996 and 2002. The CCR study was conducted in 2 phases. The purpose of phase 1 was to derive the CCR, based on a series of clinical questions in an algorithm. The second phase of the study was for prospective validation of the accuracy, reliability and clinical sensibility of the CCR in a new set of trauma patients. For our analysis, we combined subjects from both phases.

\section{Selection of participants}

The 9 participating hospitals had a combined annual ED volume of approximately 450000 patient visits. Cases were defined as all patients who received a diagnosis of a clinically important cervical spine injury. Controls were enrolled patients who were not diagnosed with a radiologically evident cervical spine injury. Additional details on subject recruitment and categorization for the CCR are described elsewhere. ${ }^{21-23}$

\section{Outcome measures}

The presence of a clinically important cervical spine injury was used as the primary outcome for our study. This was defined in the CCR study a priori as fracture or ligamentous instability. These injuries generally require internal fixation or treatment with a halo, brace or rigid collar. Radiologically evident injuries to the cervical spine were considered clinically unimportant if any of the following were observed: isolated avulsion fracture of an osteophyte, isolated fracture of a transverse process not involving the vertebral body or facet joint, isolated fracture of a spinous process not involving the lamina or a simple compression fracture of less than $25 \%$ of vertebral body height. This standardized distinction between clinically important and unimportant cervical spine injuries was based on results of a formal survey of neurosurgeons, spine surgeons, neuroradiologists and emergency physicians..$^{24}$ The 75 patients with clinically unimportant cervical spine fractures were excluded from all analyses to remain consistent with previously reported CCR study analyses.

The ethics review board of each participating hospital approved the study without need for informed consent at the time of enrolment. Radiography was ordered according to the clinical judgment of the treating physician. Not all trauma patients underwent cervical spine radiography because obligatory cervical spine imaging is not a standard Canadian practice. For those patients who did not have radiography, a registered nurse administered a structured 14-day proxy outcome measure by telephone. ${ }^{25}$

Cases were identified as trauma patients who presented to the ED with acute blunt trauma to the head or neck, met the eligibility criteria and were subsequently diagnosed with a clinically important cervical spine injury. The control population was drawn from the same cohort with the same entry criteria as the eligible cases, but who were not diagnosed with any form of radiologically evident cervical spine injury. In total there were 17208 patients included in the CCR study from the derivation and validation phases.

\section{Exposure measures}

The main exposure variables being assessed in our secondary analysis are those describing the mechanism of injury. The CCR study nurses collected information on these variables from the patient hospital charts and ambulance reports. Twelve broad categories of injury mechanism were created, with additional subcategories of covariates describing the circumstances for MVCs and falls.

\section{Imputed data values for MVC covariates}

Full details on injury mechanism variables in MVCs were not always explicitly recorded in the medical records. This resulted in missing information on estimated speed, on whether or not patients had been involved in simple rear-end collisions, head-on collisions or rollover events, and whether they were ejected or wearing a seat belt. For example, in a case in which a patient was involved in a head-on collision, and information on vehicle rollover was not explicitly recorded, this covariate was coded as "unknown" in our data set, even though the likelihood of a rollover was low.

Maintenance of unknown values in these data would result in the loss of these patients to a multivariate analysis and greatly limit its power. Hence, we imputed recodes of unknown values for subcategories of MVC mechanism if a limited number of logical assumptions could all be satisfied. The specific assumptions made a priori in assessing these data for potential recoding were as follows: that the true classification of an unknown value was more likely to be the most common or frequent response observed in that category, and that a positive response for a collision subcategory was more likely to be charted in the medical record than a negative event, such that the true value of an unknown was more likely to be the negative response. Based on these assumptions, values for unknown information in the dichotomous yes or no covariates of rear-end collision, head-on collision, rollover and ejection were imputed to permit their recoding as a "no" and seat belt use as a "yes" to enable multivariate analysis. Unknown values for speed were not recoded. The effect of recoding on the bivariate ORs for exposures was calculated.

\section{Data analysis}

The ORs of clinically important cervical spine injury and 
corresponding 95\% confidence intervals (CIs) were estimated for each major injury mechanism using unconditional logistic regression modeling. The software package SAS version 8.1 (SAS Institute, Inc.) was used. An assessment of effect by potential confounders from the CCR study was conducted using multivariate modeling. Additional models were generated for falls and MVCs to make use of the more detailed data available for these patterns of injury. MVC covariates included speed, type of collision (head-on, rollover, ejection, simple rear-end) and the use of a seat belt. Information on height of fall was available for falls. Potential confounders assessed were age and sex.

A distinct model was generated for simple rear-end collisions, since this injury mechanism would not, by definition, be associated with involvement in a rollover, ejection or head-on collision in the CCR study.

\section{Results}

\section{Characteristics of study subjects}

Among the 17208 patients enrolled in the study, 320 (2\%)

\begin{tabular}{|c|c|c|c|c|}
\hline \multirow[b]{2}{*}{ Characteristic } & \multicolumn{4}{|c|}{ Group; no. $(\%)^{*}$} \\
\hline & \multicolumn{2}{|c|}{ Cases, $n=320$} & \multicolumn{2}{|c|}{$\begin{array}{l}\text { Controls, } \\
n=16813\end{array}$} \\
\hline \multicolumn{5}{|l|}{ Sex } \\
\hline Male & 209 & $(65.3)$ & 8665 & (51.5) \\
\hline Female & 111 & $(34.7)$ & 8148 & $(48.5)$ \\
\hline \multicolumn{5}{|l|}{ Age, yr } \\
\hline Mean (SD) & 45.6 & $(20.6)$ & 37.0 & $(16.0)$ \\
\hline Range & \multicolumn{2}{|c|}{$16-94$} & \multicolumn{2}{|c|}{$15-100$} \\
\hline \multicolumn{5}{|l|}{ Mechanism of injury } \\
\hline MVC & 157 & $(49.1)$ & 11353 & $(67.5)$ \\
\hline Motorcycle collision & 5 & $(1.6)$ & 139 & $(0.8)$ \\
\hline $\begin{array}{l}\text { Pedestrian involved in } \\
\text { an MVC }\end{array}$ & 6 & (1.9) & 555 & (3.3) \\
\hline Bicycle collision & 12 & (3.8) & 467 & (2.8) \\
\hline Axial load & 38 & $(11.9)$ & 305 & (1.8) \\
\hline Falls & 80 & $(25.0)$ & 2349 & $(14.0)$ \\
\hline Other sports & 2 & $(0.6)$ & 417 & (2.5) \\
\hline Diving & 10 & (3.1) & 45 & $(0.3)$ \\
\hline All assaults & 2 & $(0.6)$ & 563 & (3.3) \\
\hline $\begin{array}{l}\text { Hit head on a fixed } \\
\text { object or struck by } \\
\text { an object }\end{array}$ & 3 & $(0.9)$ & 495 & (2.9) \\
\hline $\begin{array}{l}\text { Collisions involving } \\
\text { other motorized } \\
\text { vehicles }\end{array}$ & 5 & $(1.6)$ & 94 & $(0.6)$ \\
\hline $\begin{array}{l}\text { Other mechanisms } \\
\text { of injury }\end{array}$ & 0 & $(0.0)$ & 31 & $(0.2)$ \\
\hline
\end{tabular}

received a diagnosis of a clinically important cervical spine injury. Of these cases, $65 \%$ were men and $35 \%$ were women, with controls having a near equal distribution (i.e., $52 \%$ men and $48 \%$ women). Age ranges were similar for cases and controls (Table 1). Within the CCR study, there were 75 patients diagnosed with a clinically unimportant cervical spine fracture. These patients were excluded from further analysis.

Table 2 shows the ORs for the association between a cervical spine fracture and various injury mechanisms. The risk for cervical spine injury was found to be lower for 157 cases (49\%) in the full MVC group (OR 0.5, 95\% CI 0.4-0.6). Mechanisms of injury with statistically significant increases in risk of cervical spine fracture included axial load mechanisms, falls, diving incidents and nontraffic motorized vehicle collisions (e.g., collisions involving snowmobiles, all-terrain vehicles or personal watercraft).

Table 3 shows the frequencies and coding of MVC covariates (including those for unknown values) and their associated bivariate ORs. Recoding these unknown values resulted in changes to crash mechanism covariates (rear-end, head-on, rollover and ejection) in 16 of 157 (10\%) fracture cases and their associated controls. Recoding of seat belt use was required for an additional 7 cases (4\%). Recalculation of the bivariate ORs using the imputed codes resulted in little change in the point estimates shown in Table 3. The percent changes in ORs resulting from recoding were $0 \%$ for simple rear-end collisions, $+10 \%$ for head-on collisions, and $+2 \%$ for rollovers, ejections and seat belt use.

\section{Main results}

In fall-related injuries, the risk of cervical spine fracture increased with the height of the fall and the patient's age

\begin{tabular}{|c|c|c|}
\hline \multirow{2}{*}{$\begin{array}{l}\text { Mechanism of injury } \\
\text { MVC }\end{array}$} & \multicolumn{2}{|c|}{ OR $(95 \% \mathrm{Cl})$} \\
\hline & 0.5 & $(0.4-0.6)$ \\
\hline Motorcycle collision & 1.9 & $(0.8-4.7)$ \\
\hline Pedestrian involved in an MVC & 0.6 & $(0.3-1.3)$ \\
\hline Bicycle collision & 1.4 & $(0.8-2.4)$ \\
\hline Axial load & 7.3 & $(5.1-10.4)$ \\
\hline Falls & 2.1 & $(1.6-2.7)$ \\
\hline Other sports & 0.3 & $(0.1-1.0)$ \\
\hline Diving & 12.0 & $(6.0-24.1)$ \\
\hline All assaults & 0.2 & $(0.1-0.7)$ \\
\hline $\begin{array}{l}\text { Hit head on a fixed object or struck } \\
\text { by an object }\end{array}$ & 0.3 & $(0.1-1.0)$ \\
\hline $\begin{array}{l}\text { Collisions involving other } \\
\text { motorized vehicles }\end{array}$ & 2.8 & $(1.1-7.0)$ \\
\hline
\end{tabular}


(Table 4). Compared with low falls of less than $1 \mathrm{~m}$, patients who fell 1-3 m had a multivariate adjusted OR of 2.8 (95\% CI 1.7-4.8). Patients falling from over $3 \mathrm{~m}$ had an OR of 5.3 (95\% CI 2.8-10.0).

Frequencies of occurrence and adjusted ORs for MVC risk factors are presented in Table 5. There was only 1 person in 3694 simple rear-end collisions who sustained a cervical spine fracture. The adjusted OR associated with simple rear-end collisions was 0.02 (95\% CI 0.002-0.1). (The CCR study defined simple rear-end collisions as being hit from behind in a 2-car collision that occurred at city speeds or when 1 vehicle was stopped). The risk of cervical spine fracture increased with the posted speed and other crash characteristics. Significant increases in risk were observed for high speeds $(60-100 \mathrm{~km} / \mathrm{h})$ and highway speeds (> $100 \mathrm{~km} / \mathrm{h})($ ORs of 10.4 and 12.0 , respectively). Increased risk was associated with head-on collisions (OR 3.0, 95\% CI 1.8-5.0) and rollover events (OR 5.9, 95\%
CI 4.1-8.6). When individuals did not wear seat belts, the risk of cervical spine injury increased 3-fold (OR 3.0, 95\% CI 2.0-4.7). Ejection from the vehicle, which was a risk factor in the bivariate analysis, was not an independent risk factor in the multivariate analysis.

\section{Discussion}

Ours is one of few studies that has quantitatively assessed the utility of collecting information on the mechanism of injury for trauma patients and used multivariate techniques to estimate the independent relative risk for a specific anatomical injury associated with different injury mechanisms. The results of our study support the importance of making information on the injury event readily available to treating clinicians in EDs.

Our study demonstrates that an increased risk for cervical spine injury is associated with broad categories of

\begin{tabular}{|c|c|c|c|}
\hline MVC category & $\begin{array}{c}\text { Clinically } \\
\text { important spine } \\
\text { injury, } n=157\end{array}$ & $\begin{array}{l}\text { Controls, } \\
n=11353\end{array}$ & OR $95 \% \mathrm{Cl}$ \\
\hline \multicolumn{4}{|l|}{ Speed } \\
\hline $0=$ Stopped & 5 & 1818 & 1.00 \\
\hline $1=$ City $(<60 \mathrm{~km} / \mathrm{h})$ & 19 & 4227 & $1.63(0.61-4.38)$ \\
\hline $\begin{array}{l}2=\mathrm{High} \\
(60-100 \mathrm{~km} / \mathrm{h})\end{array}$ & 74 & 1222 & $22.01(8.87-54.59)$ \\
\hline $\begin{array}{l}3=\text { Highway } \\
(>100 \mathrm{~km} / \mathrm{h})\end{array}$ & 35 & 347 & 36.67 (14.27-94.22) \\
\hline $4=$ Unknown & 24 & 3739 & $2.33(0.89-6.12)$ \\
\hline \multicolumn{4}{|l|}{ Simple rear-end } \\
\hline $0=\mathrm{No}$ & 155 & 7310 & 1.00 \\
\hline $1=$ Yes & 1 & 3693 & $0.01(0.002-0.09)$ \\
\hline $3=$ Unknown & 1 & 350 & $0.14(0.02-0.97)$ \\
\hline \multicolumn{4}{|l|}{ Head-on collision } \\
\hline $0=\mathrm{No}$ & 127 & 9247 & 1.00 \\
\hline $1=$ Yes & 23 & 529 & $3.17(2.01-4.98)$ \\
\hline $3=$ Unknown & 7 & 1577 & $0.32(0.15-0.69)$ \\
\hline \multicolumn{4}{|l|}{ Ejection } \\
\hline $0=\mathrm{No}$ & 130 & 9987 & 1.00 \\
\hline $1=$ Yes & 14 & 93 & $11.57(6.43-20.82)$ \\
\hline $3=$ Unknown & 13 & 1273 & $0.79(0.44-1.39)$ \\
\hline \multicolumn{4}{|l|}{ Rollover } \\
\hline $0=\mathrm{No}$ & 77 & 9380 & 1.00 \\
\hline $1=$ Yes & 71 & 686 & $12.61(9.05-17.57)$ \\
\hline $3=$ Unknown & 9 & 1287 & $0.85(0.43-1.70)$ \\
\hline \multicolumn{4}{|l|}{ Seat belt } \\
\hline $0=$ Yes & 103 & 8888 & 1.00 \\
\hline $1=\mathrm{No}$ & 35 & 717 & $4.21(2.85-6.23)$ \\
\hline $3=$ Unknown & 19 & 1748 & $0.94(0.57-1.53)$ \\
\hline
\end{tabular}


injury mechanisms including axial loads (OR 7.3, 95\% CI 5.1-10.4), falls (OR 2.1, 95\% CI 1.6-2.7), diving incidents (OR 12.0, 95\% CI 6.0-24.1) and collisions involving nontraffic motorized vehicles (snowmobiles, all-terrain vehicles and personal water craft) (OR 2.8, 95\% CI 1.1-7.0).

Axial load mechanisms, which include contact sports, falling onto one's head or having a heavy object fall onto one's head, were associated with a particularly high risk of cervical spine fracture. Sports literature has cited that the most common spinal injuries are those secondary to contact sports such as football, hockey and rugby. ${ }^{26,27}$ Direct collision creates higher axial loads than the neck can withstand, leading to high injury rates. ${ }^{28}$ Diving is often cited as another significant cause of cervical spine injuries, as found in our study. Injuries resulting from diving incidents are often associated with devastating outcomes. ${ }^{29,30}$

For fall-related injuries, our study demonstrates a positive relationship between the height of a fall, increasing age and the risk for cervical spine injury, thus supporting the findings of previous work. ${ }^{31-34}$ Falls occurring from a height of 1.5 to $3 \mathrm{~m}$ and greater than $3 \mathrm{~m}$ were of high risk compared with falls less than $1 \mathrm{~m}$, with ORs of 2.8 and 5.3 , respectively. However, spine fractures did occur in falls from all heights and in all age groups..$^{35,36}$

Table 4. Adjusted odds ratio for the association between falls and clinically important cervical spine injury

\begin{tabular}{|c|c|c|c|c|c|c|c|c|}
\hline \multirow{3}{*}{$\begin{array}{l}\text { Risk factors } \\
\text { Falls }\end{array}$} & \multicolumn{4}{|c|}{ Group; no. (\%) } & \multirow[b]{2}{*}{ B } & \multirow[b]{2}{*}{ SE (ß) } & \multirow{2}{*}{\multicolumn{2}{|c|}{ Adjusted OR $(95 \% \mathrm{Cl})$}} \\
\hline & \multicolumn{2}{|c|}{ Cases, $n=80$} & \multicolumn{2}{|c|}{ Controls, $n=2349$} & & & & \\
\hline & & & & & & & & \\
\hline Low falls $(<1 \mathrm{~m})$ & 30 & (37.5) & 1351 & (57.5) & - & - & 1.00 & - \\
\hline Medium falls $(1-3 \mathrm{~m})$ & 32 & $(40.0)$ & 698 & $(29.7)$ & 1.00 & 0.3 & 2.82 & $(1.67-4.77)$ \\
\hline High falls (> $3 \mathrm{~m}$ ) & 18 & $(22.5)$ & 300 & $(12.8)$ & 1.70 & 0.3 & 5.26 & $(2.75-10.04)$ \\
\hline Age & 80 & $(100.0)$ & 2349 & $(100.0)$ & 0.05 & 0.004 & 1.05 & $(1.03-1.06)$ \\
\hline
\end{tabular}

Table 5. Adjusted odds ratio for the association between motor vehicle collision risk factors and clinically important cervical spine injury

\begin{tabular}{|c|c|c|c|c|c|c|}
\hline \multirow[b]{2}{*}{ Risk factors } & \multicolumn{2}{|c|}{ Group, no. (\%) } & \multirow[b]{2}{*}{ B } & \multirow[b]{2}{*}{ SE (ß) } & \multirow{2}{*}{\multicolumn{2}{|c|}{ Adjusted OR* $(95 \% \mathrm{Cl})$}} \\
\hline & Cases, $n=157$ & Controls, $n=11353$ & & & & \\
\hline \multicolumn{7}{|l|}{ Model 1† } \\
\hline \multicolumn{7}{|l|}{ Simple rear-end $\neq$} \\
\hline No & 156 & 7660 & & & $1.00 *$ & \\
\hline Yes & 1 & 3693 & -4.22 & 1.00 & 0.02 & $(0.002-0.10)$ \\
\hline \multicolumn{7}{|l|}{ Model $2 \S$} \\
\hline \multicolumn{7}{|l|}{ Head-on collision } \\
\hline No & 134 & 10824 & & & $1.00 *$ & \\
\hline Yes & 23 & 529 & 1.16 & 0.25 & 3.02 & $(1.83-4.97)$ \\
\hline \multicolumn{7}{|l|}{ Rollover } \\
\hline No & 86 & 10667 & & & $1.00 *$ & \\
\hline Yes & 71 & 686 & 1.71 & 0.20 & 5.90 & $(4.05-8.58)$ \\
\hline \multicolumn{7}{|l|}{ Speed } \\
\hline Stopped & 5 & 1818 & & & $1.00 *$ & \\
\hline City $(<60$ km/h) & 19 & 4227 & 0.29 & 0.51 & 1.34 & $(0.50-3.61)$ \\
\hline High $(60-100$ km/h) & 74 & 1222 & 2.34 & 0.48 & 10.37 & $(4.06-26.47)$ \\
\hline Highway (> $100 \mathrm{~km} / \mathrm{h}$ ) & 35 & 347 & 2.48 & 0.50 & 12.02 & $(4.47-32.33)$ \\
\hline Unknown & 24 & 3739 & 0.46 & 0.50 & 1.58 & $(0.60-4.20)$ \\
\hline \multicolumn{7}{|l|}{ Seat belt use } \\
\hline Yes & 103 & 8888 & & & $1.00 *$ & \\
\hline No & 54 & 2465 & 1.13 & 0.21 & 3.01 & (2.04-4.69) \\
\hline \multicolumn{7}{|c|}{$\begin{array}{l}\mathrm{Cl}=\text { confidence interval; } \mathrm{OR}=\text { odds ratio; } \mathrm{SE}=\text { standard error. } \\
* \text { Reference category. } \\
\text { tOR adjusted for age, sex and seat belt use. } \\
\text { \#Simple rear-end collision refers to a collision involving } 2 \text { cars that occurred at city speed or when } 1 \text { vehicle was stopped. } \\
\text { SOR adjusted for age and sex. }\end{array}$} \\
\hline
\end{tabular}


In Canadian trauma hospitals, MVCs cause the majority of serious injuries. ${ }^{37}$ The importance of collecting detailed information about the injury event was demonstrated by our finding that the risk for cervical spine fractures associated with our heterogeneous MVC category did not increase (OR 0.5, 95\% CI 0.4-0.6). The examination of multiple collision-related covariates revealed where significant increases and decreases in risk exist. There was a negligible risk associated with simple rear-end collisions (OR $0.02,95 \%$ CI $0.002-0.10$ ), which represented $32 \%$ of all MVC patients in our study. A higher risk was particularly observed with increased speed, rollover events (OR 5.9, 95\% CI 4.05-8.58) and head-on collisions (OR 3.02, 95\% CI 1.83-4.97).

Many researchers support the belief that triage decisions should be based on accurate information that includes a full understanding of injury mechanism. ${ }^{38} \mathrm{~A}$ study by Santana and Martinez $z^{39}$ illustrates the need for the use of both medical and automobile collision factors to provide the depth of information needed to best treat patients, and to understand their injury patterns and the sources that caused them. ${ }^{39}$ According to Peterson and colleagues, ${ }^{40}$ emergency physicians should be knowledgeable about MVCs, injury mechanisms and the management of timecritical injuries. The authors advocate that MVC injuries should be managed as any other disease, including assessing for predisposing risk factors through better understanding the biomechanics of the injury event.

One Canadian study suggested that the direction and type of impact in MVCs are strongly associated with the pattern and severity of injuries. McLellan and coworkers ${ }^{41}$ collected information from patients, ambulance attendants and police reports about the direction of impact, vehicle speeds and the degree of vehicle intrusion. They concluded that lateral impact MVCs, in particular, resulted in greater injury severity and specific patterns of injury, such as more intra-abdominal and chest injuries. Although we, unfortunately, did not collect information to identify lateral impact crashes, the work of McLellan and coauthors reinforces the need for emergency physicians to be knowledgeable about MVC injury mechanisms for the management of time-critical injuries.

In our study, the negligible risk of cervical spine injury related to simple rear-end collisions supports the need to investigate ways to minimize the use of immobilization and radiography in these patients. Although many studies have investigated the relationship between rear-impact collisions and chronic pain syndromes related to whiplash, those that looked at spine fractures found little or no increased risk. ${ }^{42-44}$
The use of seat belts is clearly a protective factor in reducing the risk of cervical spine injury. Patients who were not wearing seat belts experienced a 3 -fold increase in the risk for cervical spine injury compared with belted patients. Claytor and colleagues ${ }^{45}$ found similar results. Their results indicated that the combined use of airbags and seat belts had the greatest protective effect, compared with unrestrained occupants, with an OR of 0.19 . They found that the use of a seat belts alone had a dampened protective effect with an OR of 0.40 .

\section{Limitations}

Full details on the mechanism of injury variables that were extracted from medical records and ambulance reports were not always available for our study. Others have noted similar limitations in using information about mechanisms of injury from retrospective data collection, as well as an increased likelihood by ambulance personnel to report more detailed information on the more severely injured. ${ }^{1}$ Recoding of unknown data for the MVC covariates added to this the potential for misclassification of subjects. However, misclassification as a result of recoding in our study is likely to be nondifferential, as there was a similar distribution of unknowns for cases and controls. We believe our recoding of these variables permitted a more powerful and accurate multivariate assessment of risk ratios.

This secondary analysis of the CCR study data was inherently limited to investigating the relationship between mechanism of injury and the risk of cervical spine fractures. Data on anatomical injuries other than cervical spine injury were not available. The use of CCR data has provided an opportunity to quantitatively assess potential risk factors for cervical spine injury, and to do so using multivariate modeling provides an enhancement over previous studies. Despite the limitations of these data, our study collected more detailed information on injury mechanisms than other current studies and has more accurate data on the presence or absence of cervical spine injury.

\section{Conclusion}

Our study has clearly demonstrated the utility of collecting information on the mechanism of injury in the quantitative assessment of risk for one anatomical injury pattern. ED physicians who collect detailed information on the injury mechanism can use these data to make more effective and efficient clinical decisions when managing trauma patients.

The importance of collecting detailed information on injury mechanisms in the diagnosis and management of 
trauma patients clearly should extend beyond our study of cervical spine injuries. Logically, similar relationships exist between the injury mechanism and other key anatomical injury patterns. Continued investigation of those relationships may well support more efficient and accurate diagnosis in the care of trauma patients.

Acknowledgements: The authors thank the following additional investigators who comprise the Canadian C-Spine Rule (CCR) Study Group: The Ottawa Hospital, Ottawa, Ont. (Dr. James Worthington, Dr. Gary Greenberg, Dr. Mark Reardon and Dr. Howard Lesiuk); University of Toronto, Toronto, Ont. (Dr. Dan Cass and Dr. Glen Bandiera); London Health Sciences Centre - Victoria Campus, London, Ont. (Dr. Jon Dreyer and Dr. Mary Eisenhauer); University of Alberta Hospital, Edmonton, Alta. (Dr. Brian Holroyd); Vancouver General Hospital, Vancouver, BC (Dr. Douglas McKnight); the Royal Columbian Hospital, New Westminster, BC (Dr. Iain MacPhail); and all of the CCR study nurses.

Competing interests: None declared.

\section{References}

1. Dowd MD, McAneney C, Lacher M, et al. Maximizing the sensitivity and specificity of pediatric trauma team activation criteria. Acad Emerg Med 2000;7:1119-25.

2. Hunt RC. Is mechanism of injury dead? Prehosp Emerg Care 1999;3:70-3.

3. Daffner RH, Deeb ZL, Rothfus WE. "Fingerprints" of vertebral trauma - a unifying concept based on mechanisms. Skeletal Radiol 1986;15:518-25.

4. Fox MA, Mangiante EC, Fabian TC, et al. Pelvic fractures: an analysis of factors affecting pre-hospital triage and patient outcome. South Med J 1990;83:785-8.

5. Burstein JL, Henry MC, Alicandro JM, et al. Evidence for and impact of selective reporting of trauma triage mechanism criteria. Acad Emerg Med 1996;3:1011-5.

6. Cooper ME, Yarbrough DR, Zone-Smith L, et al. Application for field triage guidelines by pre-hospital personnel: Is mechanism of injury a valid guideline for patient triage? Am Surg 1995;61:363-7.

7. Esposito TJ, Offner PJ, Jurkovich GJ, et al. Do prehospital trauma center triage criteria identify major trauma victims? Arch Surg 1995;130:171-6.

8. Domeier RM, Evans RW, Swor RA, et al. The reliability of prehospital clinical evaluation for potential spinal injury is not affected by the mechanism of injury. Prehosp Emerg Care 1999;3:332-7.

9. Fox MA, Fabian RC, Croce MA, et al. Anatomy of the accident scene: a prospective study of injury and mortality. Am Surg 1991;57:394-7.
10. Hunt RC, Brown RL, Cline KA, et al. Comparison of motor vehicle damage documentation in emergency medical services run reports compared with photographic documentation. Ann Emerg Med 1993;22:651-6.

11. Hunt RC, Whitely TW, Allison EJ, et al. Photograph documentation of motor vehicle damage by EMTs at the scene: a prospective multicenter study in the United States. Am J Emerg Med 1997;15:233-9.

12. Dickinson ET, O'Connor RE, Krett RD. The impact of prehospital instant photography of motor vehicle crashes on receiving physician perception. Prehosp Emerg Care 1997;1:76-9.

13. Orsay EM, Martens K, Lyons E, et al. The usefulness of photographs of crash vehicles in motor vehicle trauma [abstract]. Acad Emerg Med 1995;2:447.

14. Chance GQ. Note on a flexion fracture of the spine. Br J Radiol 1948;21:452-3.

15. Mirvis SE, Young JW, Lim C, et al. Hangman's fracture: radiologic assessment in 27 cases. Radiology 1987;163:713-7.

16. Mantas JP, Burks RT. Lisfranc injuries in the athlete. Clin Sports Med 1994;13:719-30.

17. Rosenthal DI, Schwartz M, Phillips WC, et al. Fracture of the radius with instability of the wrist. AJR Am J Roentgenol 1983; 141:113-6.

18. Sanders TG, Medynski MA, Lawhorn KW. Bone contusion patterns of the knee at MR imaging: footprint of the mechanism of injury. Radiographics 2000;20:S135-51.

19. Cassada DC, Munyikwa MP, Moniz MP, et al. Acute injuries of the trachea and major bronchi: importance of early diagnosis. Ann Thorac Surg 2000;69:1563-7.

20. Stiell IG, Wells GA, Vandemheen KL, et al. The Canadian C-Spine rule for radiography in alert and stable trauma patients. JAMA 2001;286:1841-8.

21. Stiell IG, Clement CM, McKnight RD, et al. The Canadian C-Spine Rule versus the NEXUS low-risk criteria in patients with trauma. N Engl J Med 2003;349:2510-8.

22. Canadian CT Head and C-Spine (CCC) Study Group. The Canadian C-Spine Rule study for alert and stable trauma patients: I. Background and rationale. CJEM 2002;4:84-90.

23. Canadian CT Head and C-Spine (CCC) Study Group. The Canadian C-Spine Rule study for alert and stable trauma patients: II. Study objectives and methodology. CJEM 2002;4:185-93.

24. Stiell IG, Lesiuk HJ, Vandemheen K, et al. Obtaining consensus for a definition of "clinically important cervical spine injury" in the CCC Study [abstract]. Acad Emerg Med 1999;6:435.

25. Vandemheen K, Stiell IG, Brison R, et al. Validity evaluation of the cervical spine injury proxy outcome assessment tool in the CCC Study [abstract]. Acad Emerg Med 1999;6:434. 
26. Bruce DA, Schut L, Sutton LN. Brain and cervical spine injuries occurring during organized sports activities in children and adolescents. Prim Care 1984;11:175-94.

27. Torg JS. Epidemiology, pathomechanics, and prevention of athletic injuries to the cervical spine. Med Sci Sports Exerc 1985; 17:295-303.

28. Watkins RG. Neck injuries in football players. Clin Sports Med 1986;5:215-46.

29. Hwang V, Shofer FS, Durbin DR, et al. Prevalence of traumatic injuries in drowning and near drowning in children and adolescents. Arch Pediatr Adolesc Med 2003;157:50-3.

30. Schwarz N, Sim E, Nestinger K. Injuries of the thoracic vertebrae in head-first dive into water [article in German]. Unfallchirurg 2001;104:300-2.

31. Bensch FV, Kiuru MJ, Koivikko MP, et al. Spine fractures in falling accidents: analysis of multidetector CT findings. Eur Radiol 2004;14:618-24.

32. Blauth M, Lange UF, Knop C, et al. Spinal fractures in the elderly and their treatment. Orthopade 2000;29:302-17.

33. Lomoschitz FM, Blackmore CC, Mirza SK, et al. Cervical spine injuries in patients 65 years old and older: epidemiologic analysis regarding the effects of age and injury mechanism on distribution, type, and stability of injuries. AJR Am J Roentgenol 2002;178:573-7.

34. Brolin K. Neck injuries among the elderly in Sweden. Inj Control Saf Promot 2003;10:155-64.

35. Ehara S, Shimamura T. Cervical spine injury in the elderly: imaging features. Skeletal Radiol 2001;30:1-7.

36. Brown RL, Brunn MA, Garcia VF. Cervical spine injuries in children: a review of 103 patients treated consecutively at a level 1 pediatric trauma center. J Pediatr Surg 2001;36:1107-14.
37. Canadian Motor Vehicle Traffic Statistics 2003. Ottawa (ON): Transport Canada; 2003. Available: www.tc.gc.ca/roadsafety /tp/tp3322/2003/page12.htm (accessed 2008 Nov 12).

38. Hunt RC. Is Mechanism of injury dead? Prehosp Emerg Care 1999;3:70-3.

39. Santana JR, Martinez R. Accuracy of emergency physician data collection in automobile collisions. J Trauma 1995;38:583-6.

40. Peterson TD, Tilman Jolly B, Runge JW, et al. Motor vehicle safety: current concepts and challenges for emergency physicians. Ann Emerg Med 1999;34:217-20.

41. McLellan BA, Rizoli SB, Brenneman FD, et al. Injury pattern and severity in lateral motor vehicle collisions - a Canadian experience. J Trauma 1996;41:708-13.

42. Foust D, Chaffin DB, Snyder RG, et al. Proceedings of the 17th Stapp Car Crash Conference; 1973 Nov 12-13; Oklahoma City (OK): Society of Automotive Engineers; 1973.

43. Castro WH, Schilgen M, Meyer S, et al. Do "whiplash injuries" occur in low-speed rear impacts? Eur Spine J 1997;6:366-75.

44. Lövsund P, Nygren A, Salen B, et al. Neck injuries in rear end collisions among front and rear seat occupants. Proceedings of the International Council on the Biomechanics of Impacts (IRCOBI) Conference, 1988 Bergisch-Gladbach (DE): 1988. p. $319-25$.

45. Claytor B, MacLennan PA, McGwin G Jr, et al. Cervical spine injury and restraint system use in motor vehicle collisions. Spine 2004;29:386-9.

Correspondence to: Dr. Robert Brison, Emergency Medicine and Injury Research Group, Queen's University, Angada 3, Kingston General Hospital, 76 Stuart St., Kingston ON K7L 2V7; fax 613 548-1381; brisonr@kgh.kari.net 